\title{
La publicidad con ojos de niño: imaginarios infantiles y construcción crítica de significados
}

\author{
Paola Andrea Gómez-Montoya $\left({ }^{*}\right)$, Ana Castro Zubizarreta $\left({ }^{* *}\right)$ y José Ignacio Aguadez Gómez $\left(^{*}\right)$ \\ $\left(^{*}\right)$ Universidad de Cantabria - España $\left.{ }^{(*}\right)$ Universidad de Huelva - España
}

\begin{abstract}
RESUMEN
El estudio pretende recoger la mirada infantil sobre la publicidad para comprender qué sentido e influencia tiene en la vida de los niños y en la forma de construir significado a su mundo. Los niños conviven con mensajes publicitarios, de ahí nuestro interés por recoger su mirada al respecto. Para ello, hemos contado con el apoyo voluntario de 184 niños de la ciudad de Cali (Colombia) con edades comprendidas entre los 7 y los 12 años. En esta investigación se empleó la técnica de talleres, que combinó tres actividades participativas involucrando el dibujo, la escritura y la conversación espontánea. Los resultados del estudio evidencian cómo la publicidad se ha asentado silenciosamente en la vida de los niños generando un imaginario infantil que marca un estilo de vida y una cotidianidad consumista. Términos afines a la publicidad desde la perspectiva infantil son fama, consumo y marcas. Conceptos que tienen presencia en sus aspiraciones y proyecciones. El estudio recoge lo que el niño imagina sobre el tema de la publicidad y cómo la apropia invitando a reflexionar sobre el tratamiento y la generación de prácticas educativas que fomenten que los niños lean e interpreten críticamente los mensajes publicitarios.
\end{abstract}

Palabras Clave: Imaginarios, Publicidad, Procesos de escucha, Participación, Infancia.

\section{Advertising with eyes of children: imaginary children and critical construction of meanings}

\section{ABSTRACT}

The study aims to collect the children's perspective on advertising to understand what sense and influence advertising has in the lives of children and how to build meaning in their world. The children live with advertising messages, hence our interest to collect their eyes on it. For this, we have had the voluntary support of 184 children from the city of Cali (Colombia) aged between 7 and 12 years old. This research used the workshop technique, which combined three participatory activities involving drawing, writing and spontaneous conversation. The results of the study show how advertising has settled silently in the lives of children generating a childish imagery that marks a lifestyle and a consumerist every day. Terms related to advertising from the perspective of children with fame, consumption and brands. Concepts that have a presence in their aspirations and projections. The study gathers what the child imagines about advertising and how appropriate it inviting to reflect on the treatment and the generation of educational practices that encourage children to read and critically interpret the advertising messages.

Keywords: Imaginaries, Advertising, Processes of listening, Participation, Childhood.

\section{Introducción}

La publicidad ocupa hoy un sitio propio en la vida del hombre, que se acomoda a los estímulos que ésta le ofrece (Ferrer, 2002). Su presencia y dominio en la sociedad actual y en la vida cotidiana es innegable. Todos somos consumidores de productos, cuyas virtudes han sido comunicadas a través de la publicidad. Al respecto, Sassatelli (2012: 21) señala que, "hemos nacido para consumir". Un consumo que siguiendo a Buckingham (2013:15) en la sociedad actual se inicia desde el momento en el que los niños nacen, pues "las infancias contemporáneas se viven en un mundo de bienes y servicios comerciales".
La publicidad y el consumo son, por tanto, fenómenos de gran peso en la vida actual, especialmente en la infancia, lo que conlleva que los niños se conviertan en consumidores precoces, permanentes y exigentes, influyendo la publicidad radicalmente en su forma de pensar, entender y actuar en su vida cotidiana.

Si bien el consumo es necesario para subsistir, Bauman (2011) alerta sobre cómo corremos el riesgo de que el consumo se convierta en el propósito mismo de nuestra existencia, un consumo incitado desde la infancia, que hoy se desarrolla en un contexto informacional donde la inmediatez, la novedad y el acceso comunicacional marcan su crecimiento, así como su deseo de interacción continua (Pérez-Escoda, Castro y Fandos, 2016). Niños 
que forman parte de la generación $Z$, también conocida como la generación nativa de las " $\mathrm{C}$ " por las características que la definen: consumista, conectados, computarizados, comunicados, creativos, generadores de contenidos y dependientes del clic. Una generación que convive con pantallas, que se forma con base a lo que ve y que determina sus deseos y aspiraciones en relación con la información que recibe.

Los medios masivos y su bombardeo visual publicitario han construido imaginarios en los niños que se encuentran permeados por el efecto de las imágenes que les rodean y acompañan diariamente. Es así como a través de los estímulos visuales recibidos, los pequeños conciben su forma de percibir, consumir, entender el mundo y desenvolverse en él.

Por esta razón, se hace pertinente comprender, ahora más que nunca, las dinámicas que afrontan los pequeños pues, no se debe ser indiferente al entorno comunicacional en el que se desenvuelven, las numerosas pantallas y los diversos contenidos que construyen sus conocimientos, su imaginación, sus habilidades e inclusive, su pensar a partir de lo que ven. Es por ello que la investigación educativa debe aproximarse con mayor interés hacia los imaginarios que están concibiendo los niños ante tantas posibilidades sensoriales y de consumo de manera que seamos capaces de conocer y comprender mejor a la infancia actual de forma que identificando sus imaginarios sobre la publicidad y la incidencia de estos en su vida, podamos realizar propuestas educativas que empoderen a la infancia, la doten de autonomía, visibilidad y sobre todo, de una mirada crítica, ética, constructiva y responsable hacia los mensajes publicitarios y el consumo que se promueve a través de estos.

\section{La publicidad y el consumo: su presencia e influencia en los imaginarios infantiles}

La publicidad hoy día es una forma de comunicación, elaborada y avanzada, que emplea todos los recursos a su alcance para persuadir usuarios o seguidores para la compra de un producto, servicio o marca. La publicidad, sin duda, se ha convertido en un gran sistema de penetración cultural, creando y difundiendo conceptos, hábitos y mitos característicos de la sociedad de consumo, siendo una práctica comunicativa que adquiere su significación dentro del contexto de una economía de libre mercado, lo que permite que el propio discurso social se convierta en un fenómeno de transmisión de los valores hegemónicos del propio ámbito social donde se halla inmerso (Hellín, 2006).

Compartimos el posicionamiento de Santamarina (2000:103) cuando expresa que "la publicidad como forma particular de comunicación en el consumo organiza una forma de concebir la realidad, porque detrás de una manera de mirar, opera una manera de pensar que es la que organiza y programa a la mirada misma". En la misma línea, consideramos que los anuncios publicitarios fabrican valores y modelos de vida que intentan ser impuestos de forma discreta. En este sentido, Moro (2007) incide en que la publicidad no es neutra, sino que reinterpreta la realidad social y tiende a reconstruirla según sus intereses. El consumo está claramente vinculado con la creación de las identidades personales y con la realidad social de los individuos, puesto que los productos, los anuncios y las marcas ayudan a construir la personalidad y a dotar al individuo de un determinado sentido de sí mismo.

De esta manera es necesario ser conscientes de que la publicidad es en la actualidad, uno de los instrumentos mediáticos más poderosos de la sociedad de consumo. Autores como Armstrong y Kotler (1996), y Eguizábal (2004) han realizado sendas propuestas sobre las funciones que puede poseer la publicidad.
Destacamos la de Martín-Requero (2008) que clasifica en dos categorías la publicidad destinada a menores, por un lado, la publicidad educativa o con causa social que surge con la pretensión de actuar como transmisora de aprendizajes en valores que promuevan la mejora de la realidad social. En el extremo contrario, encontramos la publicidad de consumo o de comunicación comercial, que favorece el consumo de productos y pretende atraer la atención de los niños para incitarles el deseo de adquirir determinados productos. A partir de ellas es posible explicitar cómo de forma indefectible la publicidad influye en el imaginario infantil y la construcción de sentidos y significados de los niños sobre el mundo.

Autores como Castoriadis (1983), Andazlúa (2008), Morin (2011) y Rincón (2013) han abordado el estudio de los imaginarios infantiles definiendo estos como el conjunto de normas y símbolos que comparte la infancia como colectivo y, que, pese a su carácter imaginado, estructuran la experiencia social de los pequeños abarcando las ideas, imágenes, actitudes y afectos que definen su manera de concebir el mundo y su existencia.

Consideramos que los imaginarios sociales, concretamente los del colectivo infantil, permiten identificar las ideas, creencias y representaciones de los niños sobre temas que les afectan, lo que puede favorecer una mejor comprensión de la infancia. Al respecto, consideramos que esta línea de investigación que se ubicaría bajo el paradigma de la escucha a la infancia supone identificar el imaginario infantil sobre la publicidad, un imaginario que influye sobre sus deseos y en la construcción de las identidades individuales y sociales. Es casi inexistente el estudio de cómo la publicidad contribuye a modelar la imagen que los niños se hacen del mundo. De hecho, se han estudiado las representaciones sociales sobre la infancia en los anuncios publicitarios (Gómez y Blanco, 2005), la influencia de las imágenes mentales generadas por la publicidad en la mente del público infantil según la naturaleza del estímulo (Arroyo-Almaraz y García-García, 2014), la influencia de la publicidad en el consumo infantil (Teruel, 2014), pero no hemos encontrado estudios que cuenten con la perspectiva infantil sobre la publicidad y cómo ésta influye en el imaginario de los niños y el sentido y significado que confieren a sus experiencias personales y sociales.

Los procesos de escucha a la infancia: los niños como informantes y constructores de significados

Indudablemente, el referente principal de la participación infantil es la Convención de los derechos del Niño (1989), en la que se aborda el derecho del niño a ser escuchado, participar y ser tenido en cuenta en aquellos aspectos que influyen en su vida, si bien, de forma tan general que, tal y como apuntan Alfageme, Cantos y Martínez, (2003: 33) "pueden dejar muy poco margen para su efectivo ejercicio”. En todo caso, esta Carta Magna remarca la conceptualización de una infancia con derechos y capacidades que visibilice a los niños como sujetos de derechos individuales, jurídicos, civiles y sociales, presentándolos siguiendo a Altimir (2010: 30) "como portadores y constructores de culturas propias y, por tanto, participantes activos en la organización de su identidad y de su autonomía". Se entiende de este modo a los niños y niñas como actores sociales y no como ejecutores o consentidores de algo, aspecto que ha querido destacarse cuando autores como Alfageme, Cantos, y Martínez (2003) acuñan el término "participación protagónica".

Asimismo, la citada Convención en su artículo 17 señala "la importante función que desempeñan los medios de comunicación en el desarrollo de los niños, velando los Estados porque 
el niño tenga acceso a información y material procedentes de diversas fuentes nacionales e internacionales, en especial la información y el material que tengan por finalidad promover su bienestar social, espiritual y moral y su salud física y mental". En este sentido, los medios de comunicación y concretamente, la publicidad educativa se erige como un elemento fundamental para la promoción de una infancia con derechos, ética y responsable, si solicitan los puntos de vista de los niños sobre situaciones o temáticas que les afectan, dándoles la oportunidad de ser escuchados y tenidos en cuenta. Recoger su propia perspectiva ayudará a evitar estereotipos sobre la infancia, así como un punto de vista adultocentrista que según Buckingham (2013: 22) "no suelen incluir las voces de los mismos niños, ni procuran explicar sus puntos de vista: se trata, esencialmente, de un discurso generado por adultos en nombre de los niños". Por ello, y siguiendo a Tonucci (1989), es preciso realizar procesos de escucha y participación infantil sobre este foco de atención concreta: la publicidad, que nos ayude a identificar lo que los niños realmente piensan, sin intermediarios, sus creencias, deseos e impresiones que, transmitidas desde el mundo publicitario influyen en la construcción de los sentidos y significados que confieren a lo que les rodea. Esta premisa es la que inspira propósito principal de nuestro estudio: Recoger la mirada infantil sobre la publicidad para comprender qué sentido e influencia tiene la publicidad en la vida de los niños y en la forma de construir sentido y significado a su mundo.

\section{Metodología}

\section{Muestra}

Los niños que participaron en esta investigación fueron 184 escolares de primaria con edades comprendidas entre los 7 a 13 años de Cali (Colombia) y pertenecientes a un centro privado y otro público, seleccionados en esta etapa porque demuestran generalmente mayor capacidad de concentración, destacada apertura mental y valiosa sinceridad para dar respuestas.

Antes de iniciar las actividades se les consultó su deseo de cooperación en la investigación, con previo consentimiento informado de sus familias, priorizando los derechos del niño y su libertad de decidir sobre su participación. Por lo tanto, el muestreo empleado fue por conveniencia, a partir de la selección del grupo de estudio de manera intencional por cumplir las características puntuales que requería el trabajo.

\section{Diseño metodológico}

La investigación se ubica dentro del paradigma cualitativo debido al marcado interés de la investigación por interpretar los elementos inmersos de la realidad de los escolares que hacen parte del proyecto. El estudio se define de tipo descriptivo y de carácter trasversal pues se obtuvo información en un momento y tiempo definido (curso escolar 2016). Se inscribe bajo el enfoque sociocrítico ya que pretende dar voz y valor a las aportaciones infantiles utilizando técnicas participativas, amigas de los niños (Grover, 2004).

\section{Técnica de recolección de datos}

La técnica utilizada fueron los "Talleres", debido a que se requerían herramientas que identificaran de manera colectiva los imaginarios que poseen los niños sobre la publicidad, y que permitiera descubrir a la vez su construcción de significados (lo que piensan, sienten o reflexionan sobre ella). Esta técnica de taller tiene la posibilidad pedagógica de integrar la teoría con la práctica, además genera valiosa información al investigador (Maya, 2007).

De igual forma, estimula el aprendizaje por descubrimiento, la opinión tanto individual como colectiva y la reflexión personal. Los talleres se crearon inspirados en tres técnicas proyectivas como la asociación, la temática y la expresiva. Se construyeron los siguientes instrumentos para la recolección de información:

- Taller Listado de Palabras: esta actividad se denominó "Conceptualizando - Ando" y se basó en la técnica proyectiva de la asociación, que consiste en enunciar palabras orales o escritas para generar respuestas espontáneas (Chávez, 2007), adaptándose de la siguiente manera: los escolares recibieron un listado de 17 palabras relacionadas con la publicidad, donde debían definir con sus propias palabras los términos solicitados. La selección de palabras se efectuó considerando la relación con el tema y la realidad cotidiana de los niños, conociendo previamente su contexto y los mensajes a los que generalmente han estado expuestos.

- Taller Dibujo de Aspiraciones: esta actividad se denominó "marcas que proyectan mi vida" y se basó en la técnica proyectiva de la expresión, la cual consiste en solicitar al sujeto una consigna escrita o verbal, que debe responder de forma artística. manifestando así percepciones e imágenes mentales sobre determinados aspectos (Chávez, 2007). El dibujo es uno de los instrumentos más empleados en la investigación con niños. Ortiz, Prats y Baylina (2012) consideran que "es la forma natural de comunicación y de expresión personal que motiva y estimula la participación de los pequeños durante el estudio, generando un ambiente relajado y divertido" permitiendo a su vez conseguir que se hagan conscientes de las cualidades visuales de su entorno y cotidianidad (Hart, 2001). Para este estudio el dibujo de aspiraciones tenía como propósito identificar la influencia de la publicidad y el consumo en los anhelos de los niños. En esta actividad cada niño recibió una hoja con una línea en la mitad de ella, y se les solicitó que en un lado dibujaran lo que querían ser de mayores y en el otro lado las cosas que deseaban tener en un futuro lejano.

- Taller Escrito a Destinatario: esta actividad se denominó "marcas que marcan" y se basó en la técnica proyectiva de la temática, Consistió en solicitar a los niños que escribieran una carta a su marca favorita. El objetivo de este taller era develar lo que piensan y sienten los niños sobre sus marcas preferidas.

De esta manera se puede apreciar con estos tres talleres que en el presente estudio se tomó el riesgo de adaptar y combinar técnicas optando por el multimétodo que combine técnicas visuales, orales y escritas (Castro, Ezquerra y Argos, 2016) que faciliten un mayor acercamiento a la perspectiva infantil y que favorezca el tener una visión más holística del tema a investigar (Ortiz, Prats y Baylina, 2012).

\section{Procedimiento}

Las fases que han orientado el desarrollo del estudio han sido las siguientes:

Fase 1. Consideraciones éticas y obtención del consentimiento informado de los referentes adultos del niño y el consentimiento informado del propio niño. En el desarrollo de la investigación siempre se 
tuvieron presentes las consideraciones éticas correspondientes a un estudio con niños, velando en todo momento por su seguridad, libertad y capacidad de decisión de los niños en torno a su participación en el estudio.

Con el objeto de obtener el consentimiento informado de los referentes adultos para los niños, se procedió a establecer un diálogo presencial con los colegios seleccionados presentando al equipo directivo y al profesorado los detalles de la investigación, al igual que sus beneficios. Posteriormente, se procedió a informar a las familias de los objetivos y propósitos del estudio haciendo énfasis en la participación voluntaria. Finalmente, se presentó a los niños las razones por las cuales se requiere su colaboración aclarándoles que su participación era voluntaria y que si en el transcurso del estudio deseaban no continuar podrían hacerlo libremente.

Fase 2 La recogida de datos a través de los talleres. La dirección de ambos colegios, tanto público como privado, estableció los horarios y momentos en los cuales se podrían desarrollar los ta- lleres. Cada taller fue efectuado en las aulas de cada grupo, para mantener su confianza y en la presencia de sus profesoras.

\section{Análisis de la información}

Para analizar la información obtenida a través de los tres talleres (listado de palabras, dibujo de aspiraciones y escrito a destinatario) se contó con el apoyo de la herramienta de NVivo. En primera instancia se consideraron los objetivos del estudio, así como el marco teórico desarrollado, de manera que el estudio mantuviese relación y coherencia. Posteriormente se analizó cada taller por separado identificando las categorías emergentes de cada uno, para luego identificar las categorías recurrentes durante todo el documento y los tres instrumentos. Así se identificaron 17 categorías (véase figura 1): publicidad, marcas, imaginarios, creencias, ideas, símbolos, apreciaciones, pensamiento, interpretación, significado, opinión, reflexión, deseo, sentir, comprender, influencia y consumo.

Figura 1: Proceso de categorización de los datos. Fuente: elaboración propia

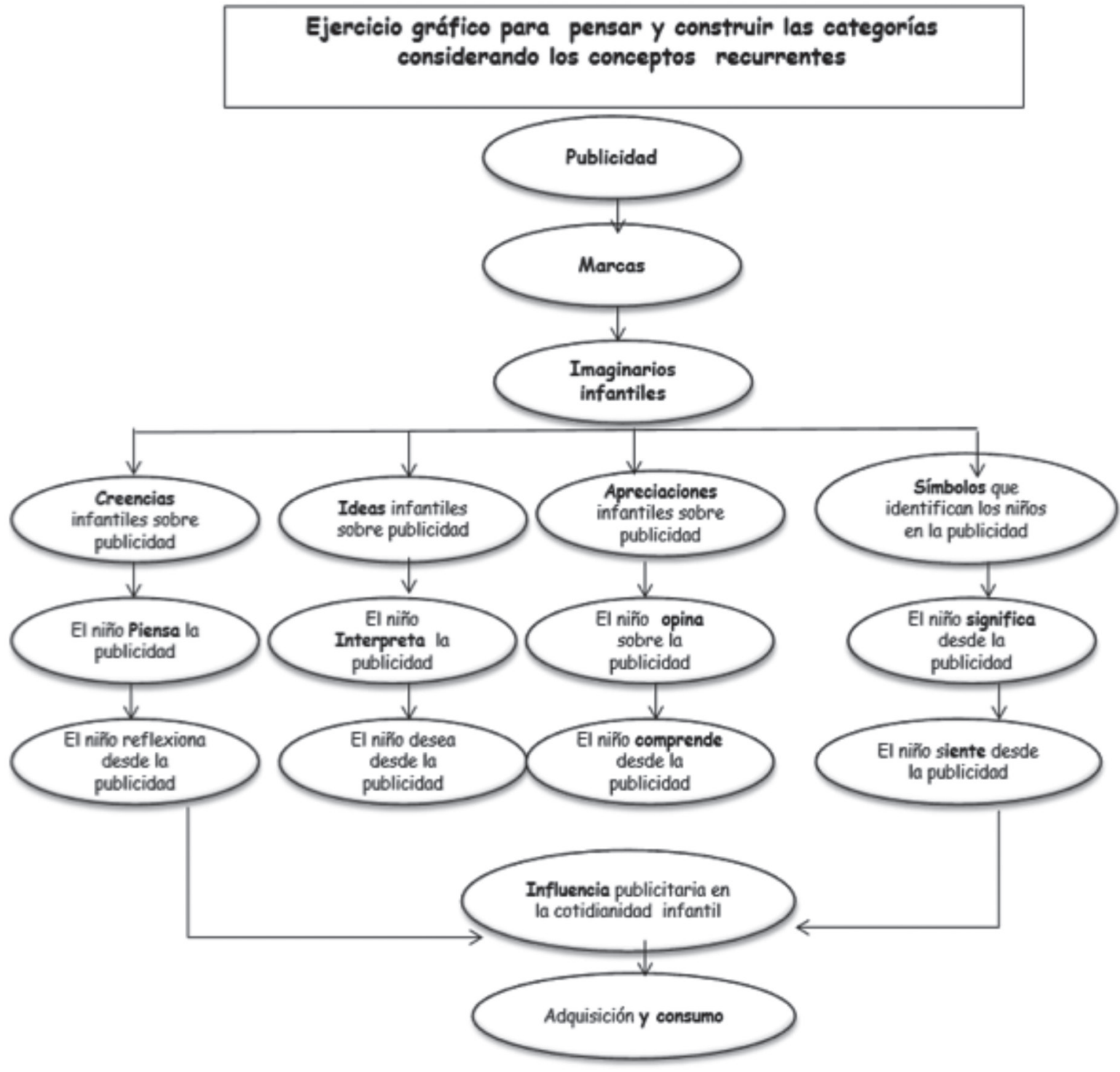


Las categorías mencionadas con mayor frecuencia fueron los soportes para analizar el conjunto y establecer las categorías en común y desde allí se tuvieron los insumos para establecer las principales unidades de análisis del estudio para efectuar el cruce de información y obtener los resultados. Por lo tanto y consecuente con el proceso metodológico, se establecieron las macrocategorías siguientes:

- Significados, sentidos y símbolos que los niños atribuyen a la publicidad.

- Deseos que genera la publicidad en los niños.

- Influencia de la publicidad en la cotidianidad de los niños.

\section{Resultados}

Presentamos a continuación el análisis de resultados atendiendo a las tres macrocategorías presentadas con anterioridad con la triangulación de la información obtenida a través de los tres talleres realizados. Es importante señalar que para la presentación de los trabajos elaborados por los niños en algunos casos se debió recurrir a la transcripción para dar claridad al lector, respetando la literalidad de las aportaciones infantiles, su expresión espontánea y su particular arquitectura para escribir y dibujar.

\section{- Significados, sentidos y símbolos que los niños atribuyen a la publicidad:}

A través del taller "Conceptualizando Ando", identificamos el significado que los niños otorgan al concepto "publicidad" solicitándoles una definición. El término no les resultó lejano o desconocido para ellos. Tenían claridad para plasmar el concepto presentándose coincidencias en sus definiciones.

Es así como los escolares del curso de 11 y 12 años relacionan la publicidad con información, venta, medios de comunicación, publicación, compras, y propaganda. De esta forma respondía un alumno cuando señalaba que: la publicidad "es publicar productos para que la gente los compre". Otras respuestas ilustrativas son las siguientes: "Es una imagen para vender"; "Es algo que se muestra a las demás personas". "Medio que se utiliza para promover un producto".
Entre tanto, los niños de entre 7 y 10 años relacionaron más el término con anuncios o propaganda. Así lo expresaban: "Anuncios de productos". "Sinónimo de propaganda". Conocimiento de productos y actividades". También expresaron que sirve para informarse y animarse a comprar incluyendo a la Red Internet como un medio distribuidor de publicidad. Como dato interesante, en algo que sí coincidieron todos los cursos fue en expresar que la publicidad es una facilitadora de la fama.

Se puede apreciar que los niños sí entienden sobre el tema de publicidad, la definen con claridad y hacen relaciones interesantes de la palabra como: venta y compra; publicar y promover; anuncios y propaganda; productos e información. Se evidencia así que es una palabra para ellos cotidiana y familiar pues reconocen con facilidad que la identifican en los medios, en la calle y hasta en internet, creen además que a través de ella se logra la fama una expresión recurrente en los talleres. La publicidad de esta manera ha cobrado otro significado para ellos, donde no solo se venden o compran productos sino también, se vende y compra visibilidad y reconocimiento de personas.

En el taller Escrito a destinatario "Marcas que Marcan" también se evidencian elementos interesantes para esta categoría. Los niños seleccionaron su marca favorita y le escribieron una carta comentado lo que les gustaba de ella, pero, además, podían enviarle algún mensaje. Fue interesante ver que los niños de inmediato sabían qué marca seleccionarían para escribir. Las cartas en general fueron sorpresivas, pues se logró evidenciar la influencia de la publicidad en su vida dando un especial significado a los productos que tienen de ellas y su relación cotidiana. Desde esta actividad los niños les escribieron a marcas incluyendo en sus mensajes tanto textos como dibujos que complementan su mensaje. Ilustrativo es el siguiente mensaje:

“Quiero que sepas que eres mí marca favorita gracias a tus juguetes y el parque. Ya tengo una colección de juguetes desde que tenía 6 años, eres la mejor marca, me gusta el que están dando y es Mario Bross. Voy cuando puedo los domingos con mi hermano y mi mamá". (7 años) (McDonalds marca de comida rápida).

Figura 2: Mensaje destinado a una marca

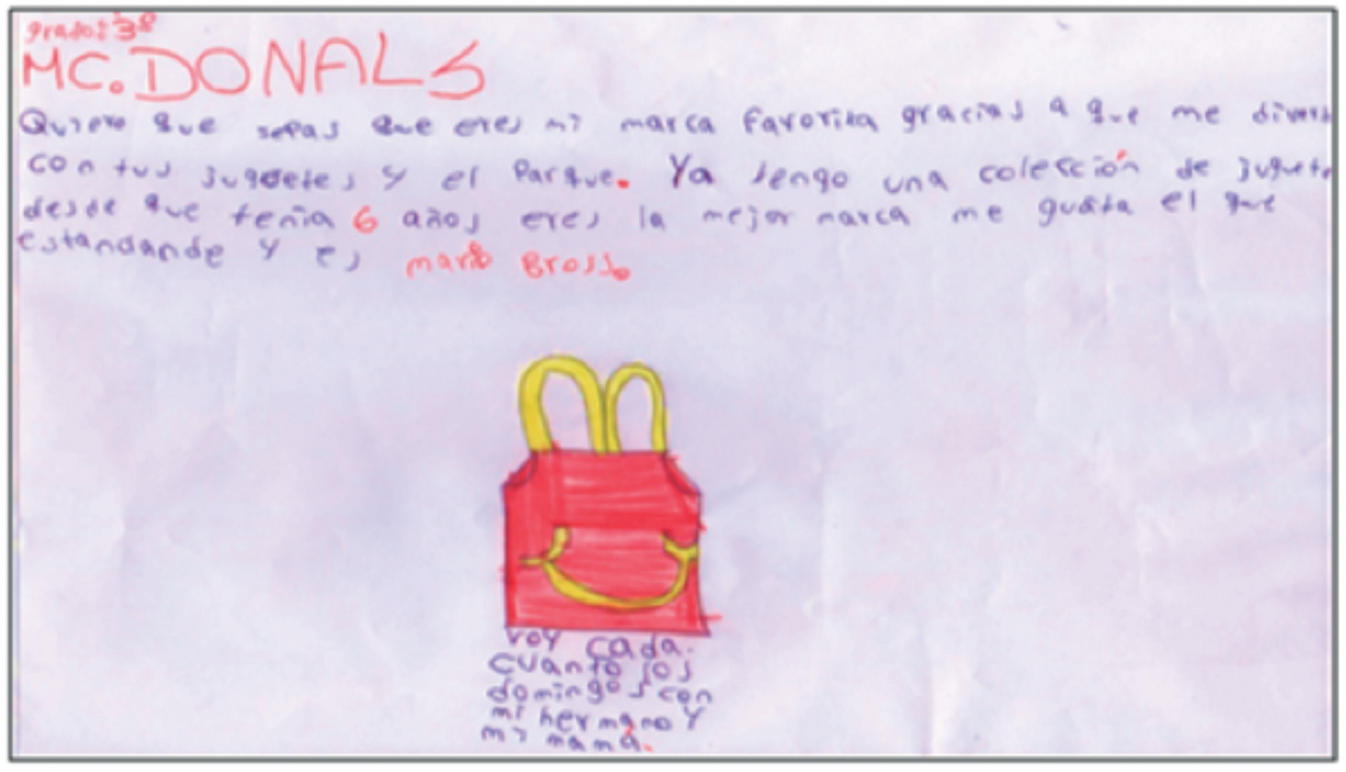


Entre las marcas favoritas se encuentran las categorías de ropa, zapatos, tecnología, comida, almacenes de ropa, bebidas gaseosas, canales y personajes de dibujos animados. A través de sus escritos revelan varios aspectos como: sus gustos, sus emociones, su relación, su sentimiento, sus creencias y hasta sus aspiraciones, lo que demuestra que los niños no son pasivos frente a la publicidad y que, por el contrario, están comprometidos en generar constante significado y sentido a lo que poseen y pueden llegar a poseer cuando toman aprecio a una marca. Mostramos a continuación extractos de algunos relatos:

"Me gustaría que la marca conociera que juego futbol, que su marca es la mejor, que sirve para cada deporte y que es tan buena que hasta Cristiano Ronaldo la usa". (Nike marca de ropa deportiva)

"Me gustaría que la marca conociera que yo la utilizo permanentemente. Me gustaría que ellos supieran que la utilizo en los mejores momentos: fiestas, matrimonios, etc. (Natura, marca brasilera de cosméticos)

"Me gustaría que sepa que la tomo cuando hace calor y siempre me refresca. Cada vez que voy a pasear siempre la tomo. Que siempre la voy a comprar. Que me encanta su sabor. Que la compro cada fin de semana. (Pony Malta marca de bebida gaseosa de Malta)

Es así como los pequeños logran dar cualidades simbólicas a los productos $\mathrm{u}$ objetos relacionadas con ellas, haciendo referencia a sus positivas experiencias, comentando con naturalidad los gratos recuerdos o momentos vividos con la marca, pero a su vez, expresando su orgullo y lealtad por ella cuando la compran, manifestando que les brinda felicidad o alegría cuando tienen contacto con la marca. Esto se aprecia cuando los niños comen- tan sobre sus hábitos o rituales con ellas o cuando afirman que utilizan las marcas en momentos o actividades importantes, o en el caso mencionado del niño que envía un mensaje destinado a una marca de comida rápida donde especifica que desde los 6 años colecciona los juguetes que acompañan a la comida. La publicidad y las marcas son parte de los imaginarios infantiles, ya que son el insumo de su cotidianidad, las dibujan de memoria e identifican sus logos como si formara parte del aprendizaje de la vida.

\section{- Deseos que genera la publicidad en los niños:}

Otra categoría recurrente fue el de deseos que genera la publicidad en los niños, una línea muy relacionada con la anterior y que apunta a la cuestión social del consumo en la infancia, ya que, desde ella, al parecer, han encontrado la posibilidad de hablar con naturalidad de comprar y pedir, puesto que al consultarles a los niños se refleja de manera permanente su deseo de tener, influenciados por los medios y muy especialmente desde lo proyectado en la publicidad. Desde los talleres se puede apreciar que los pequeños ya cuentan con una cultura publicitaria y están por completo familiarizados con ella y que forma parte de su discurso cotidiano representando para ellos una manera de expresarse socialmente, en el recreo, en el aula o en su hogar.

En el taller Dibujo de aspiraciones "Proyecto mi Vida", se observó cómo la mayoría de los niños expresan sus aspiraciones vitales influenciados por los medios de comunicación y especialmente por la publicidad. Muchos de sus sueños tienen el nombre de una marca, generando incluso con ellas sus proyecciones. En esta actividad se les entregó a los niños una hoja para dibujar en la parte izquierda lo que deseaban ser de mayores y en la derecha escribir o dibujar lo que deseaban tener a futuro. Veamos algunos ejemplos de lo que ellos manifestaron desear:

Figura 3: Dibujo de aspiraciones, quiero ser y quiero tener. Ejemplo 1

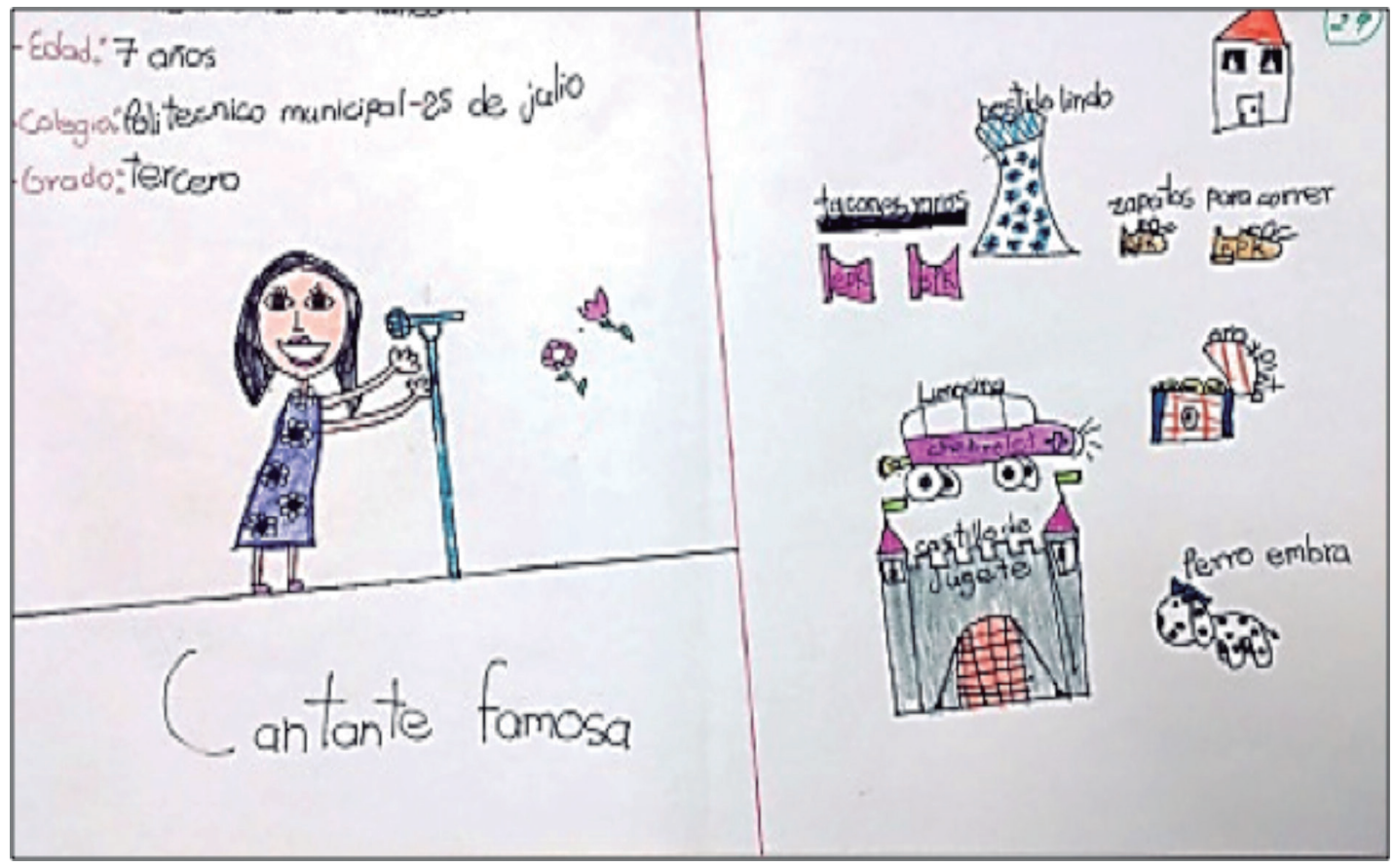

“Quiere ser: una cantante famosa. Quiere tener: ropa y zapatos EPK, tacones raros, vestido, casa, castillo, un perro hembra, oro, plata y una limusina". 
Figura 4: Dibujo de aspiraciones, quiero ser y quiero tener. Ejemplo 2

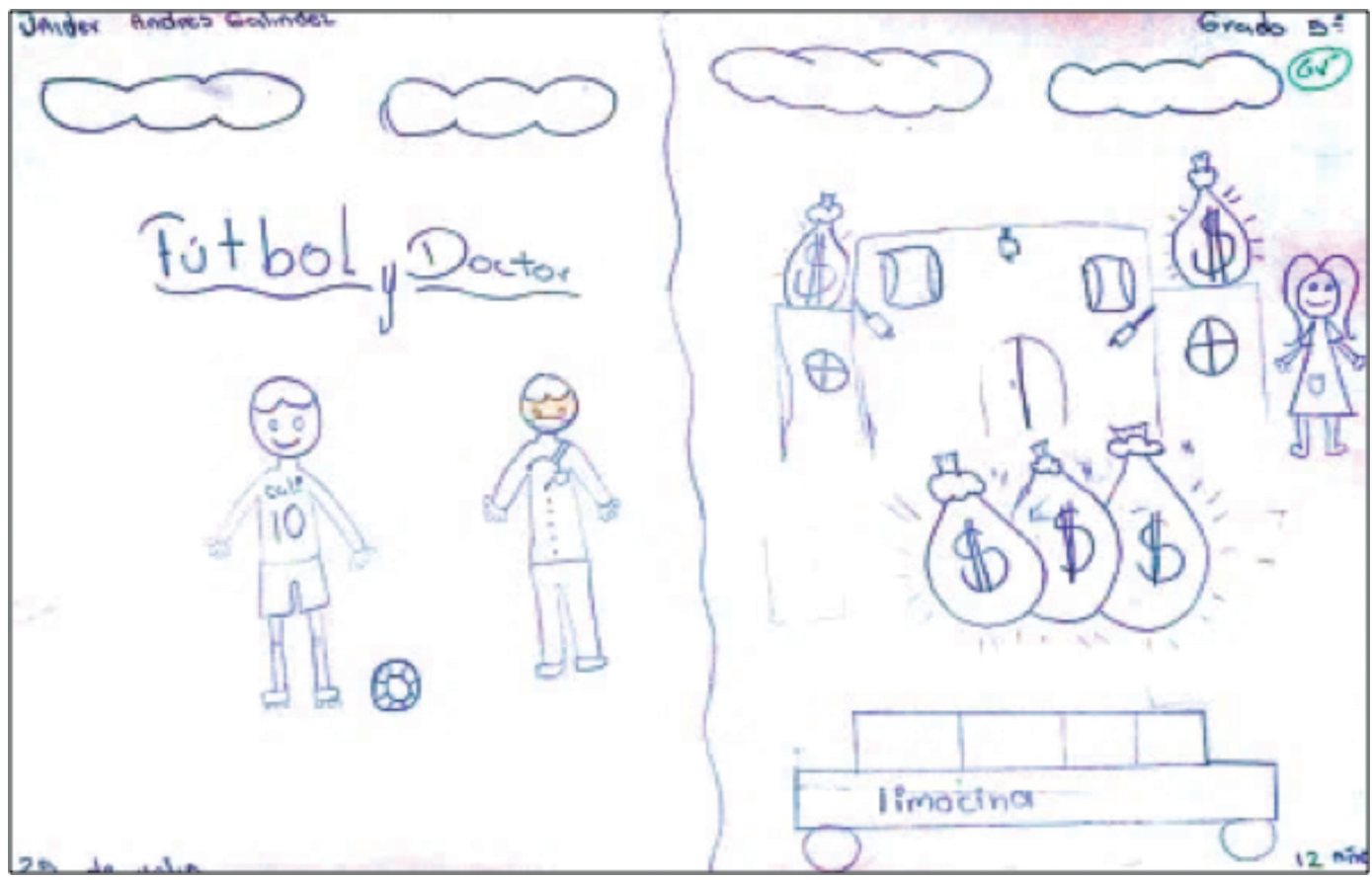

“Quiere ser: futbolista. Quiere tener: una mansión y un BMW o un Mercedes Benz, una mascota, una familia y tener hijos".

Los dibujos de los niños presentaron elementos coincidentes. Entre las profesiones con mayor preferencia de niños y niñas fue la de ser futbolista y porteros. En conversaciones espontáneas las niñas manifestaron querer ser profesionales en este deporte porque sus padres son fanáticos del fútbol y no se lo pierden por televisión, lo que las ha animado a practicarlo con "seriedad" dicen. Otras profesiones con numerosos seguidores fue la veterinaria, ya que manifestaron que les gustaría ser como César Millán el "Encantador de perros", y le siguió la de policías y médicos. Otras preferencias que expresaron fue la de ser cantante, modelos actores y actrices, tres profesiones que prevalecen en los dos colegios. Su razón fue la misma en todos los niños: ser reconocidos y famosos, un deseo constante tanto en sus dibujos como en sus expresiones. También se debe señalar que entre sus gustos mencionaron otras profesiones, en poca frecuencia, pero que es conveniente destacar porque ya encuentran seguidores como: ser Miss Universo, másterchef o youtuber. En relación con las cosas que deseaban poseer encontramos tres elementos que se presentan como constantes: una casa, un coche y una piscina, y como dispositivos electrónicos sus prioridades fueron: el celular, la tablet, el computador, Xbox y el televisor. Todos estos anhelos no eran descritos de manera escueta, la mayoría iban acompañados con una especificación de marcas y aspiraciones puntuales.

Entre lo más pedido se encuentra las casas y especialmente las mansiones, pero el mayor lugar de deseo fue para los coches y las limusinas. Además, los niños fueron muy específicos con las marcas que deseaban tener como: Lamborghini, Bugatti, Ferrari, BMW, Volvo, Camaro Mercedes Benz, Nissan, Mazda, Kia, Toyota y Chevrolet. En este punto se debe destacar la capacidad de los niños para identificar y recordar marcas de coches. En tecnología también fueron exigentes y claros con las marcas que deseaban y entre las más nombradas se encuentran: Samsung, Huawei, Iphone, Sony, Galaxy, Panasonic, Nintendo Wii, Motorola.
Los dibujos que realizaron con mayor frecuencia los niños en el taller fueron bolsas de dinero y el signo (\$), también mencionaron desear oro y una gran mayoría quiere tener mascotas. Finalmente, en sus mensajes y dibujos plasmaban sus exigencias en relación con sus productos de consumo y que quedan reflejados en estos extractos: "quiero que sea último modelo", "que sea de diseñador", "quiero una buena vida", "que sea lujosa”, "quiero ser rico", "tener fans", "tener fama".

Con este ejercicio se puede ver una radiografía de cómo las aspiraciones del niño han cambiado y las prioridades de su futuro son otras, especialmente la de convertirse en rico y famoso. Al parecer el acceso a las multipantallas y sus contenidos publicitarios les ha facilitado a los niños encontrar su referente e inspiración para proyectarse, identificando en cantantes, modelos, deportistas y actores sus modelos a seguir, quienes han brindado el ejemplo del dinero, el consumismo, y la fama.

- Influencia de la publicidad en la cotidianidad de los niños

La diversidad de los medios de comunicación y la intromisión inevitable de las marcas en la vida cotidiana de los niños les ha proporcionado un mayor conocimiento sobre la publicidad, además de una variada opción de preferencia de marcas.

La publicidad está inserta en su cotidianeidad influyendo en sus vidas y marcando momentos que los niños perciben como importantes. En este sentido, un niño comentaba cómo cuando usaba unas playeras de una determinada marca se divierte mucho. Otro expresa cómo la asistencia a un centro de comida rápida se convierte en un lugar de encuentro familiar. [...] "voy cuando puedo los domingos con mi hermano y mi mamá".

Los niños se presentan como consumidores capaces, ya que tienen un amplio manejo y apropiación de las marcas que les han cautivado o han despertado su interés. Son ellos los interesados en navegar en las páginas: "busco mucho sus productos por internet y en el centro comercial compro"; en comunicarse con ellas si es necesario, en ahorrar para comprar, en pedir a sus padres con exclusividad: "a mí siempre me compran de tu ropa en diciembre me van a comprar una muda de ropa bien bonita"; .en reconocer la trascendencia que tienen las marcas en su vidas: "la 
utilizo en los mejores momentos: fiestas, matrimonios, mi mamá me lo compra cuando yo se lo pido... sus olores son deliciosos" y en mantener las costumbres y en crear lazos afectivos con ellas: "quiero darte las gracias porque me das vida con tus comidas".

Por otro lado, el taller "Conceptualizando Ando" recoge la voz escrita precisamente sobre qué significado confieren los niños a otros términos relacionados directamente con la publicidad y que han logrado inferir desde su experiencia diaria. Presentamos a continuación una selección de ellos y las respectivas definiciones dadas por los pequeños:

Tabla 1: Conceptualización de términos vinculados con la publicidad por parte de los niños

\begin{tabular}{ll}
\hline \multicolumn{1}{c}{ CONCEPTO } & DEFINICIÓN \\
\hline Comercial & "Publicidad de televisión donde salen anuncios de comida o aparatos". \\
& "Mostrar alguna cosa para comercializarlo". \\
Marca: & "Lo pasan por el televisor cuando se acaba la película y te pasan propaganda para que compres". \\
& "Es el signo o símbolo que hace identifiquemos algo o un producto como marca de camisas, zapatos y otras cosas". \\
& "Es algo para diferenciar los productos de alguna empresa a la de ellos y esto con el fin de que compren solo de \\
Consumidor: & "Pella marca y no compren de otros". \\
& "Alguien que tiene muchas cosas". \\
Comprar: & "Es gastar dinero en cosas que necesitas o no las necesitas tanto". \\
& "Cuando uno coge algo y lo paga". \\
Etiqueta: & "Gastar euros y dólares". \\
& "Muestra la talla o la plata que se necesita para comprarlo". \\
Moda: & "Es combrar a alguien en Facebook". \\
& "Lo que las persona para poner el código de barras, el precio". \\
Fama: & "Es ropa moderna que hacen diseñadores famosos. \\
& "Persona rica y con fans". \\
& "Es cuando uno tiene mucho dinero".
\end{tabular}

Sus definiciones ponen de manifiesto la claridad conceptual y el significado que confieren a cada término presentado. A pesar de que los niños participantes son de diferentes edades y contextos en sus respuestas se evidencian el establecimiento de relaciones para afrontar la definición, el empleo de términos o palabras recurrentes como comprar, gastar, dinero y fama y cómo el colectivo infantil posee un rico imaginario sobre la publicidad en el que se identifican creencias, y hábitos de su vida cotidiana relacionados con el consumo.

\section{Conclusiones}

El desarrollo y crecimiento de los niños en una cultura consumista es, hoy en día, un hecho indiscutible. Los resultados de nuestro estudio muestran cómo los niños son consumidores competentes actuales y de futuro ya que a través de la publicidad adquieren conocimientos, actitudes e ideas sobre marcas y productos todavía inalcanzables para ellos. Estos resultados nos acercan a los postulados de Buckingham (2016) cuando afirma que la publicidad influye en el entorno de niños y niñas y en sus experiencias sociales y culturales.

Como investigadores pretendíamos recoger la mirada infantil sobre la publicidad para comprender qué sentido e influencia tiene la publicidad en la vida de los niños y en la forma de construir sentido y significado a su mundo. Para ello, se ha generado un espacio para escuchar, respetar y dar importancia a sus apreciaciones, de manera que primara el punto de vista del niño y no la perspectiva adulta, imperante en muchos estudios. Coincidimos con Castro, Ezquerra y Argos (2016) cuando señalan que este tipo de estudios pueden ayudar a generar un conocimiento emergente sobre la infancia actual y su manera de conferir significado al mundo en el que se desarrolla.

Para lograr captar el pensamiento espontáneo y sincero de los niños se lograron desarrollar instrumentos propios con téc- nicas participativas amigas de la infancia. Los resultados positivos de la implementación de las técnicas creadas para recoger la voz de los niños confirman la validez de estos instrumentos en la línea de lo expresado por autores como Clark y Moss (2001), Dockett y Perry (2005) y Blaisdell (2012) quien apunta al reto de generar técnicas participativas totalmente inclusivas destinadas al colectivo infantil.

Los resultados del estudio ponen de manifiesto cómo la publicidad direcciona la vida de los niños hoy, tanto o más que los medios de comunicación. Así las marcas y sus contenidos son la pauta para inspirar y generar modelos de vida a corto y largo plazo pues, como lo indicaba uno de los niños, la publicidad es una "propaganda para saber qué existe y qué no existe", lo que evidencia la importancia de ella en sus vidas, pues a través de la publicidad, al parecer, legitiman la realidad. Solo lo que aparece allí es aprobado desde su perspectiva, de manera que productos, marcas y personajes son los protagonistas que merecen toda la atención.

Términos afines a la publicidad desde la perspectiva infantil son fama, consumo y marcas. Conceptos que tienen presencia en sus aspiraciones y proyecciones. La fama desde la mirada infantil es algo que proviene de la publicidad, que permite tener reconocimiento, lo que hará posible tener dinero, seguidores y a su vez lograr todo lo material, lo cual deberá ir acompañado con marcas. Así estos escolares y la gran mayoría que hizo parte del proyecto coincidieron en sus deseos, en gran medida inspirados por la publicidad y movidos por el deseo de fama.

Por su parte, las marcas para los niños representan estatus, calidad y elegancia tal y como expresaban: Marca es "algo fino", "Nike, es tan buena que hasta Cristiano Ronaldo la usa". Se puede inferir con lo que se ve aquí, que la marca es otro elemento importante que se debe destacar pues desearlo, adquirirla o tenerla representa mucho para los niños, tanto que es hoy más que un nombre, y pasó a ser incluso un sentimiento, un sueño y un estilo 
de vida, pues tenerlas los hace felices, dicen que la aman, le dan las gracias y otros se proyectan con ellas.

Estos resultados evidencian cómo la publicidad, tal y como afirmaba (Aguaded, 1995), se ha asentado silenciosamente en la vida de los niños generando un imaginario infantil creado a través de la publicidad que marca un estilo de vida y una cotidianeidad consumista cuyos valores e ideales pueden estar alejados de uno de los fines de la educación por excelencia: el tipo de persona y ciudadano que queremos ayudar a formar. Se percibe a la luz de los resultados obtenidos un descuido de políticas educativas que puedan suavizar la emisión de anuncios proconsumistas, o bien que fomenten el desarrollo de una vertiente en ciernes, la publicidad educativa siguiendo la aportación de Martín-Requero (2008).

El estudio recoge lo que el niño imagina sobre el tema de la publicidad y cómo la apropia brindando una fotografía sobre la publicidad y su relación con los niños desde la mirada infantil, invitando a reflexionar sobre el tratamiento y prácticas que generan quienes hacen la publicidad hoy y cómo otros agentes educativos tradicionales por excelencia: escuela y familia, pueden ayudar a que los niños lean e interpreten críticamente los mensajes publicitarios. Por ello, a raíz de esta investigación consideramos que una línea de trabajo interesante sería la edupublicidad, es decir, la integración de la publicidad en la escuela para conseguir que los niños y niñas de hoy sean capaces de interpretar y utilizar los mensajes publicitarios para construir una ciudadanía más responsable, ética y participativa. Como futuras líneas de trabajo se plantea el contrastar los resultados obtenidos con otros contextos fuera de Colombia.

\section{Referencias bibliográficas}

Aguaded, J.I. (Ed.) (1995). Publicidad... ¿cómo la vemos?, Comunicar, 5

Alfageme, E., Cantos, R. y Martínez, M. (2003). De la participación al protagonismo infantil. Propuestas para la acción. Madrid: Plataforma de Organizaciones de Infancia (POI).

Altamir, D. (2010). Cómo escuchar a la infancia. Barcelona: Octaedro.

Andazlúa, R. (2008). Pensar al Sujeto a Partir de Castoriadis. Fragmentos del Caos. Buenos Aire: Biblos.

Armstrong, G., y Kotler, P. (1996). Mercadotecnia. México: Prentice-Hall.

Arroyo-Almaraz, I. y García-García, F. (2014). Influencia de las imágenes mentales generadas por la publicidad en la mente del público infantil según la naturaleza del estímulo. Palabra Clave 18(1), 212-238.

Bauman, Z. (2011). Collateral Damage: social inequalities in a global age. Cambridge: Malden: Polity Press.

Blaisdell, C. (2012). Inclusive or exclusive participation: paradigmatic tensions in the Mosaic Approach and implications for childhood research. Childhoods Today 5(3). Disponible en http://www.childhoodstoday.org/article.php?id=68

Buckingham, D. (2013). La Infancia Materialista. Crecer en la cultura consumista. Madrid: Morata.

Castoriadis, C. (1983). La institución imaginaria de la sociedad. Barcelona: Tusquets.

Castro, A., Ezquerra, P. y Argos J. (2016). Procesos de escucha y participación de los niños en el marco de la educación infantil: Una revisión de la investigación. Educación XX1, 19(2), 105-126
Chávez, A. (2007). Técnicas Proyectivas. Universidad de Colima. Disponible en https://comenio.files.wordpress.com/2007/08/ tecnicas_proyectivas.pdf.

Clark, A. y Moss, P. (2001). Listening to Young Children: The Mosaic Approach. London: National Children's Bureau.

Dockett, S. y Perry, B. (2005). 'You Need to Know How to Play Safe': children's experiences of starting school. Contemporary Issues in Early Childhood, 6(1), 4-18.

Eguizábal, R. (2004). La comunicación publicitaria. Antecedentes y tendencias en la sociedad de la información y el conocimiento. Sevilla: Comunicación Social ediciones y publicaciones.

Ferrer, E. (2002). Publicidad y comunicación. México: Fondo de cultura económica.

Gómez, J.M. y Blanco, J. (2005). Los niños en la publicidad. Una propuesta de categorización de las representaciones sociales sobre la infancia en los anuncios televisivos, Zer, 19, 53-76.

Grover, S. (2004). Why won't they listen to us? On giving power and voice to children participating in social research. Childhood, 11(1), 81-93.

Hart, R. (2001). La participación de los niños en el desarrollo sostenible. Barcelona: UNICEF.

Hellin, P. (2006). Publicidad y valores posmodernos. Madrid: Sirandae Editorial.

Martín Requero, M. ํㅡ. (2008). Comunicación con causas las causas de la Comunicación Sevilla: Ed. Comunicación Social.

Matthews, H., Limb, M., y Taylor, M. (1998). La Geografía de los niños: algunas consideraciones éticas y metodológicas para el trabajo de proyectos y tesis. Revista de Geografía en Educación Superior, 22(3), 318.

Maya, A. (2007). El taller educativo ¿Qué es? Fundamentos, cómo organizarlo y dirigirlo, cómo evaluarlo. Botá: Aula abierta Magisterio.

Morin, E. (2011). Cultura de massas no século XX: o espírito do tempo. Rio de Janeiro: Forense-Universitaria.

Moro, M. (2007). Educación en valores a través de la publicidad de televisión. Comunicar, 15(28), 28, 183-189.

Organización de las Naciones Unidas. (1989). Convención de los Derechos del Niño. Disponible en http:// goo.gl/5b2JYR

Ortiz, A., Prats, M., y Baylina, M. (2012). Métodos visuales y geografías de la infancia: dibujando el entorno cotidiano. Scripta Nova. Revista Electrónica de Geografía y Ciencias Sociales. [En línea], XVI (400). vol. XVI, no 400. Disponible en: http://www. ub.es/geocrit/sn/sn-400.htm.

Pérez-Escoda, A., Castro-Zubizarreta, A. y Fandos, M. (2016). La competencia digital de la Generación Z: claves para su introducción curricular en la Educación Primaria, Comunicar, 49, 71-79.

Powell, M., y Smith, A. (2009). Children participation rights in research, Childhood, 16(1), 124-142.

Rincón, C. (2013). Imaginarios de infancia, políticas públicas y prácticas pedagógicas. (Tesis doctoral). México: Universidad Nacional Autónoma de México.

Santamarina, C. (2000). Nuevos conflictos de las mujeres en la sociedad de consumo. España: Facultad de Ciencias Políticas y Sociología.

Sassatelli, R. (2012). Consumo, Cultura y Sociedad, Amorrortu. Buenos Aires: Amorrortu.

Teruel, S. (2014). Influencia de la publicidad televisiva en los menores (Tesis doctoral). Málaga: Universidad de Málaga.

Tonucci, F. (1989). Con ojos de niño. Barcelona: Barcanova. 
